\title{
Investigating the Relationship between Parenting Styles and Juvenile Delinquent Behaviour
}

\author{
Muhammad Syawal Amran*, Norhida Anor Basri \\ Faculty of Education, Universiti Kebangsaan Malaysia, 43600 Selangor, Malaysia
}

Received July 29, 2020; Revised October 7, 2020; Accepted October 30, 2020

\section{Cite This Paper in the following Citation Styles}

(a): 11] Muhammad Syawal Amran, Norhida Anor Basri, "Investigating the Relationship between Parenting Styles and Juvenile Delinquent Behaviour," Universal Journal of Educational Research, Vol. 8, No. 11A, pp. 25 - 32, 2020. DOI: 10.13189/ujer.2020.082104.

(b): Muhammad Syawal Amran, Norhida Anor Basri (2020). Investigating the Relationship between Parenting Styles and Juvenile Delinquent Behaviour. Universal Journal of Educational Research, 8(11A), 25 - 32. DOI: 10.13189/ujer.2020.082104.

Copyright $\bigcirc 2020$ by authors, all rights reserved. Authors agree that this article remains permanently open access under the terms of the Creative Commons Attribution License 4.0 International License

\begin{abstract}
Parenting style is very important in influencing students' juvenile delinquent behaviour so that it will not go against the norm of society and rules regulated. Therefore, this study examined on parenting styles and its relationship to juvenile delinquent behaviour using mixed method design. Surveys were distributed to 187 students and interview sessions were conducted to five students to explore the relationship between parenting styles (authoritative, authoritarian, permissive) and delinquent behaviours (verbal, physical, sexual, anti-social). Study result shows that there is a significant relation between authoritarian parenting style and juvenile delinquent behaviour. However, authoritative and permissive parenting styles do not show any significant relationship. This means that parents who like to control and restrict the freedom of their children influence the behavior of juvenile students. Data collected from the interview shows that authoritarian type of parents have a lot more influence towards juvenile delinquent behaviour. This is because authoritarian parenting style prioritizes a high control level to make the children listen to them in making decisions causing the children to feel conflicted, less communicative and lost their trust in parents. Therefore, this study will explain on how parents play an important role in having faith in their children so that they will be responsible and smart in limiting and preserving their behaviour.
\end{abstract}

Keywords Parenting Styles, Juvenile Delinquent Behaviour, Students

\section{Introduction}

Parents play an important role in making sure their child's psychology is well-developed especially in terms of behaviour, emotions, cognitive, social interaction, moral and academic achievement. Parents' failure in educating their children will affect their future and open up risks for them to engage in behavioral problems [5,14,21]. This is because lack of knowledge and parenting skills may disrupt family system from functioning well and lead to problematic behavior among children [25,30]. Moreover, rigid working schedule that limits communication between parents and child, autocratic traits shown while educating their child and neglecting childrens' needs can also result in problematic behaviours [26,30]. Hence, parenting styles are the right key in ensuring family institution's stable functioning as well as avoiding the children from going astrayed into the delinquent behaviour situations.

According to past researches, parenting styles play a main role in deciding the morph of a child's attitude, behavior and thought [4]. Authoritative parenting style has a strong influence towards students' attitude and behaviour [11]. Parenting styles that stress on openness and two way communication between parents and children will shape the persona of the kids. It happens because these parenting styles hold power in shaping the character, growth, development and commitment as well as trust in a child[13]. Besides, it is also because these parenting styles are also used in educating children which in turns will affect their behaviour and development [29]. 
However, parenting styles that are practiced nowadays do not really befit the children's development which later gives effect on their psychological stress, social and moral functionings [19,41]. The inability of parents to guide their children's upbringing might end up producing children with less self-confidence in making decisions, low self pride, passive actions, no physical and mental strength to control themselves and insufficient guidelines that they could opt for delinquent behaviours $[28,40]$. That is why family institutions must be enhanced because family is the basic social unit that provides the human capital for the growth of a country.

The shortcoming in educating children sparks interest for them to seek their parents' attention and release stress by taking action without thinking of the consequences which will lead to a severe criminal act [19]. A criminal act is a behaviour that goes against the moral values, societal norms or rules that have been fixed by a particular institution. If this issue is not given the right surveillance it will exhibit the signals of unstability and unsustainable well-being of a community. In fact, it will pave their way as a threat to the safety of the country [35,38]. This is aligned with past researches that explained students who involved in misbehaviour conducts such as murder, theft, rape and so forth have shown an alarming increase in crime rates which can threaten a country's safety [45].

In this research, researcher investigated the relationship between parenting styles and juvenile delinquent behaviours. Past research focused on parenting styles among families with low socioeconomic status, academic achievement and social behaviour issues [26,27,37]. However, the research are providing inadequate insight on students who committed risky behaviours among juvenile students. This is significant because parenting style is one of the factors that contribute to problematic behaviours among juvenile students. Past research explained that autocratic parenting styles influence the students' behaviours, verbal and physical [19].

Moreover, permissive parenting style leads their children to engage in social misconducts such as drugs abuse, property crimes and vandalism. Therefore, it is clear that juvenile students are a group of people that requires attention as they pose possible threats to the peace of the society and country $[16,38]$.

This study is an effort from researchers to study the relationship between parenting styles and delinquent behaviour of juvenile students. This is because parenting style which is used is really important in shaping the children's behaviour. If parents fail to educate their children in the right way, there will be more cases of children with anger management issues, passive attitude and further contribute to a lot of troubles to adapt themselves in the real world $[4,19]$. The effects will give a big impact on school as an educational institution and social control agent [44] and they could become a threat towards the human resource and the sustainability of a country $[19,26]$.

\section{Literature Review}

Parenting style is a process of care, nurturing, guiding and educating from parents to their children. Parenting style is an important aspect that influences the well-being of children and creating a functional family [4]. According to Baumrind [7] and Maccorby [18], practice and behaviour that are implemented to educate children will have a direct effect towards emotion, social and intellect of the child. This shows that parents should adopt a suitable parenting style to secure the psychological state and socio-emotion of a child [32,41]. Therefore, parenting style is very crucial in making sure children's development especially when it comes to nurturing good behavioral aspect and have a high level moral value.

Baumrind [8] stated that there are three parenting styles which are authoritarian, authoritative, and permissive. All of these parenting styles affect students' psychological development specifically behavioral aspect in different ways [11]. Authoritative parenting style is found to suit the children's needs the best. This parenting style has a high responsive level but low demand as parents put more focus on care, autonomy and negotiate rules with the child $[12,25]$. Meanwhile, authoritarian parenting style has a low responsive level yet high demand because it concerned with the compliance towards parents, practiced control approach, punishment and rigid rules. In addition, permissive parenting style gives full freedom to children in making decisions and taking action without any restrictions but at the same time does not neglecting the children's basic needs.

Past researches explained that authoritarian parenting style affects children's behavior as they have to obey the parents' instructions without being given the freedom to make their own decision [12,20]. This causes the children to feel constrained and did not get enough control over activities that they love. Later on, it could result to lower confidence among children in exploring new opportunities, inability to adapt themselves to a challenging social network and feeling bored with their life[33]. Other than that, permissive parents do not really pay attention in setting rules and limits in the house [12]. The consequence of permissive parenting style is that it invites the internalisation problems, be it in their house, school, community or even academic performance [9].

Based on the past researches, it showed that parenting style is significant in determining the shape of behaviours of students[23,42]. Parents' failure in giving attention to the parenting styles will lead to the feeling of lack of love, dissatisfied towards parents' action and rebellious attitude until they start to resort to a place or friend to express their thoughts and behaviours. Expressed behaviours such as skipping schools, engaging in vandalisme, theft, and drug 
abused are the results of latent which can lead to the increment of crime rate all over the country [30,36,41].

Juvenile behaviour refers to failure of a student in obeying rules that are set and committing in actions that do not abide the law. A student can be categorized as delinquent when they act in a contradicting, misleading and negative manner to break the rules and crime laws [36]. This behavioural misconduct contradicts the societal norms and cannot be accepted as they are still students. Problematic behaviours potray the image of bad action, damaged morality and negligence of being responsible [31]. Meanwhile, problematic behaviours are also deciphered as actions that violate the ethics in religion and life norms that bring harms to soul and damage good values in one's self [1].

That is why parents play a significant role in ensuring family institution that is working well. It is because parents are the responsible persons to shape and nurture the good values in children's life [43]. Unconcerned family and lack of communication between parents and children could create a gap and unhealthy emotions [24]. This ended up making the children's souls to become fragile and vulnerable to negative social attraction. They are unable to cope and defend themselves from the challenges and stress. In line with that, parenting knowledge is really needed in educating the children. Children's education should be fitted parallelly to behaviour development so that they can have good personality and produce youth that will contribute to the nation's productivity.

\section{Methodology}

This study employed mixed method, sequential and explanatory design. According to Creswell and Clark [9], mixed method is a procedure of data collection and analysis that combine both quantitative and qualitative research in one study to understand and answer the research questions.

\section{Participants}

Survey

We collected survey data from a purposive sample of juvenile students $(\mathrm{N}=187)$. To obtain study participants, we contacted four juvenile schools management via email and invited their students to participate in this survey. We also required participants to fill the informed consent form before conducting this research.

\section{Qualitative Interviews}

Participants were asked to join for the interview. However, only twenty three of them accepted the interview session and were asked to fill the invitation form. Unfortunately, only five individuals responded to the invitation form and agreed to participate in the interviews.
Five participants involved in behavioral issues stated that their parents exercised authoriatarian parenting style.

\section{Instrument}

Survey

Questionnaire that was used in this research was adapted from Baumrind Questionnaire (1966) [6] to measure parenting styles which consisted of 30 questions and Inventory Delinquency Scale Junger (1997) [15] to measure risky behaviours which consisted of 40 questions. Baumrind's Parenting Style Questionnaire (1996) were divided into two parts: Part A was the three components of parenting styles which are authoritarian, authoritative and permissive; and Part B was the four components of risky behaviours which are verbal, physical, sexual and anti-social.

Parenting style instrument was scored on a 5-point Likert scale ( $1=$ strongly disagree, $5=$ strongly agree). A higher score indicated a higher competence in parenting skills and vice versa. Meanwhile, Junger's Delinquency Scale was scored on a 5-point Likert scale $(1=$ never, $5=$ always). A higher score indicated a higher frequency in committing behavioural misconduct and vice versa.

All 70 items from existing instruments which were used in the questionnaire were checked and verified by the experts. The reliability analysis yielded a high Cronbach's alpha of more than .70 for each components (Landell, 1977) [17]. It supports the use of this reliable and valid instrument for this research purposes.

Table 1. Reliability value of variable items

\begin{tabular}{cccc}
\hline $\begin{array}{c}\text { Parenting } \\
\text { Styles }\end{array}$ & $\begin{array}{c}\text { Alpha } \\
\text { Cronbach } \\
\text { Value }\end{array}$ & $\begin{array}{c}\text { Delinquent } \\
\text { behaviours }\end{array}$ & $\begin{array}{c}\text { Alpha } \\
\text { Cronbach } \\
\text { Value }\end{array}$ \\
\hline Authoritarian & .841 & Verbal & .745 \\
Authoritative & .822 & Physical & .914 \\
Permissive & .827 & Sexual & .868 \\
& & Anti-social & .930 \\
\hline Total & .900 & Total & .967 \\
\hline
\end{tabular}

\section{Qualitative Interviews}

For the qualitative data, researcher did an interview with five respondents that were chosen from juvenile students' grouping who stated that their parents used an authoritarian parenting style. Respondents provided feedback to the protocol questions that were stated. Through individual interview, researcher collected in depth information from the individuals. According to Morgan [10], through an interview, researcher can receive a more comprehensive data and it gives a higher chance for the respondents to express their opinion openly and freely while reducing the bias from others' opinion. Questions that were presented in this protocol were open-ended questions and it was run in the form of discussion. Therefore, respondents were free to give their feedback according to their own view. Table 2 
below shows the protocol questions that were given to the respondents.

However, qualitative data were collected based on two semi-structured for individual interviews. Galletta's [2] work guided the development of the interview questions which include building rapport with participants, effective phasing and timing of probing questions. Researchers conducted interviews in the school. The interviews were recorded and took approximately 40 minutes. As an exploratory, mixed-methods study, the interview prompts were developed based on an analysis of students' quantitative response. The interviews emphasized on gathering inputs on "How is your parents' authoritarian parenting style?" and "How can authoritarian parenting styles influence delinquent behaviours until you are charged with prison sentence?" (Table 2 shows semistructured interview questions). The framework guided the qualitative analysis, which involved familiarizing with data, identifying main themes, indexing themes, coding, mapping and charting themes for interpretive purposes [34]. In addition, researchers used open, axial, and selective coding to organize and interpret interview data. Researchers gathered both quantitative and qualitative responses to highlight the main research questions and compared participants' responses to check for disconfirming evidence and discrepancies. Besides, we had triangulated the data across participants to see the reliability and validity of the survey data. Lastly, we also used member check to verify and explore the interpretation of participants' responses.

Table 2. Semi - Structured Interview Questions

\begin{tabular}{cl}
\hline \multicolumn{1}{c}{ Interview Questions } \\
\hline 1 & How is your parents' authoritarian parenting style? \\
\hline 2 & $\begin{array}{l}\text { How can authoritarian parenting styles influence delinquent } \\
\text { behaviours until you are charged with prison sentence? }\end{array}$ \\
\hline
\end{tabular}

\section{Findings}

The findings reported three aspects which are i) types of parenting style that was practiced, ii) types of delinquent behaviours among juvenile students and iii) relationship between parenting styles and delinquent behaviours among juvenile students.

Table 3. Types of parenting styles among juvenile students

\begin{tabular}{|c|c|c|c|c|}
\hline Parenting Styles & $\mathrm{N}$ & $\mathrm{M}$ & $\mathrm{SD}$ & Interpretation \\
\hline Authoritarian & 187 & 3.49 & .454 & Average \\
\hline Authoritative & 187 & 3.76 & .482 & High \\
\hline Permissive & 187 & 3.49 & .463 & Average \\
\hline
\end{tabular}

Table 3 shows parenting styles which are authoritarian, autoritative and permissive. The result shows the mean score of authoritative parenting style which is 3.76 (SD = 0.482 ), followed by mean score of authoritarian parenting style which is $3.49(\mathrm{SD}=0.454)$ and permissive parenting style which is 3.49 ( $\mathrm{SD}=0.463)$. The results show that mean score for authoritative parenting style is high, while authoritarian and permissive parenting styles are average. Based on the study analysis, it indicates that authoritative parenting style is the style that was practiced in educating the juvenile students rather than authoritarian and permissive.

Table 4. Types of Delinquent behaviours among Juvenile Students

\begin{tabular}{|c|c|c|c|c|}
\hline $\begin{array}{c}\text { Stage of } \\
\text { Delinquent } \\
\text { behaviours }\end{array}$ & $\mathbf{N}$ & $\mathbf{M}$ & $\mathbf{S D}$ & Interpretation \\
\hline Verbal & 187 & 2.39 & .824 & Low \\
\hline Physical & 187 & 2.23 & .672 & Low \\
\hline Sexual & 187 & 2.07 & .940 & Low \\
\hline Anti-social & 187 & 2.61 & .683 & Average \\
\hline
\end{tabular}

Table 4 shows delinquent behaviours that consist of four components which are verbal behaviours, physical behaviours, sexual behaviours and anti-social behaviours. The result shows the mean score and standard deviation for verbal behaviour $($ Mean $=2.39, \mathrm{SD}=0.824)$, physical behaviour (Mean $=2.23, \mathrm{SD}=0.672$ ), sexual behaviour (Mean $=2.07, \mathrm{SD}=0.683$ ) which are low and anti-social behaviour score (Mean $=2.61, \mathrm{SD}=0.683$ ) which is average. This means that anti-social behaviour is the common behaviour that is done by juvenile students rather than verbal, physical and sexual behaviours. Anti-social behaviour is aggressive acts such as smoking, addicted to marijuana, abusing drugs, taking ecstacy pills and hallucinogens, riding motorcycle without license and not wearing helmet.

Table 5. Relation between Parenting Styles and Delinquent behaviours among Juvenile Students

\begin{tabular}{|c|c|c|c|c|}
\hline $\begin{array}{c}\text { Parenting } \\
\text { Styles }\end{array}$ & Verbal & Physical & Sexual & Anti-social \\
\hline Authoritarian & $-0.175^{*}$ & $-.158^{*}$ & $-.274^{*}$ & $-.148^{*}$ \\
\hline Authoritative & $.160^{*}$ & -0.64 & -055 & .042 \\
\hline Permissive & .080 & .080 & .003 & .129 \\
\hline
\end{tabular}

Table 5 shows the relationships between parenting styles and delinquent behaviours among juvenile students. The result shows that there is a negative significant relationship between authoritarian parenting style and verbal behaviour $(\mathrm{r}=-0.175, \mathrm{p}=0.016)$, physical behaviour $(\mathrm{r}=-0.158, \mathrm{p}=$ $0.031)$, sexual behaviour $(\mathrm{r}=-0.274, \mathrm{p}=0.000)$ and anti-social behaviour $(r=-0.148, p=0.043)$. It means that parents who practiced authoritarian parenting style are associated with lesser behaviours on verbal, physical, sexual and anti-social among juvenile students.

For authoritative parenting style, it shows there is a positive relationships with verbal behaviour $(r=0.160, p=$ 0.028). However, there is no significant relationship between authoritative parenting style and physical behaviour $(r=0.064, p=0.388)$, sexual behaviour $(r=$ 
$-0.55, \mathrm{p}=0.457)$, and anti-social behaviour $(\mathrm{r}=0.042, \mathrm{p}=$ $0.564)$. It means that parents who practiced authoritative style can influence the delinquent verbal behaviour rather than other delinquent behaviours among juvenile students.

On the other hand, permissive parenting style shows that there is no significant relation with verbal behaviour $(\mathrm{r}=$ $0.109, \mathrm{p}=0.137)$, physical behaviour $(\mathrm{r}=0.080, \mathrm{p}=$ $0.278)$, sexual behaviour $(\mathrm{r}=-0.003, \mathrm{p}=0.966)$ and anti-social behaviour $(r=0.129, p=0.077)$. This shows permissive parenting style does not associate with juvenile students' behaviours.

How is your parents' authoritarian educating style?

Based on the qualitative research, it shows that the education pattern used by parents is authoritarian style. The participants in this study stated that they had a good relationship with their parents, but were not friendly and they had to abide to their parents' rules. This is alligned with R4 findings... My parents are strict... so I'm afraid to say what I want.... and R3.. my mother loves to nag and babble.. sometimes I become stress because I have to listen to them.. From these findings, it is clear that their parents controlled their children's behaviours as the children had to follow the orders and had no autonomy in making their own decisions.

How can authoritarian parenting styles influence delinquent behaviours until charged with prison sentence?

This study shows that the participants were having difficulty in communicating with their parents especially when it came to feelings and problems that they faced. Parents' behaviours that just gave orders and controlled the participants had inflicted pressure on them. This is because parents do not listen to the needs of their children until they had to resort to people who they think could be trusted. This problem has made parents as no longer a choice for them to depend on as they no longer feel comfortable and trust in their parents. R2..My mother is busy managing my siblings until I was not given any attention.. I feel stress and seek for friends that are more fun to be with.. R3 Mom does not care about anything that I do.. like loitering around and smoking outside.. as long as I get back home if not she will get mad...RI my father loves to label me as a useless son and scolds me in front of other people... based on all three responses, it shows that parents' failure to communicate and be a good listener are some of the factors that influenced the delinquent behaviours of the participants.

\section{Discussion}

Parenting styles give psychological effect towards children especially with their behaviours [29]. Results show that juvenile students stated that the most common parenting style is authoritative. It means that their parents give them their trust and chance to make their own decision, have tolerant, and strict. Past researches explained that parents involvement in guiding their children helps children to develop positive thinking, high confidence, creative and excel in education when their authoritative parents are more rational, tolerant and always give them support $[11,41]$. This is because this parenting style will give comfort to their children as they are always loved, given attention and a way of democratic parenting style.

However, findings show that authoritarian style is a parenting style that contributes towards the starting of the delinquent behaviours among students. This study comes in line with the research $[22,42]$ where they found that authoritarian parenting style tends to instil negativity among children as they received education that is too constrained and forceful. Based on this findings, it shows that this parenting style has become one of the factors that produced delinquent behaviours among juvenile students. This is because authoritarian parenting style puts the discipline first, sets the standard behaviours that should be followed, inclines to strictness, prioritizes rules and gives little chance for them to plan for themselves on their own $[12,20,29]$. Moreover, this parenting style caused the child to abide to the rules fixed for them to avoid being punished and get penalized from parents. Therefore, the behaviours that they show are temporary and they did it without full effort nor willingness.

The result from qualitative research also shows that authoritarian parenting style leads to delinquent behaviours of juvenile students. This is because parents do not give their attention towards the needs of their children's emotions, thus making children feel the tensions in communicating with their parents until they lost their trust. These are a few of the factors that affect children's behaviours. This situation has caused them to seek for space to release their tension and involved themselves with peers who shared the same experience to express their feelings and beliefs. This could somehow lift up the burden that they carry in their heart as they now have a place to pour out their feelings. Armsden and Greenberg (1987)[3] argued that soul's emptiness felt and freedom sought by them have exposed them to the negative elements. The freedom they seek is occupied by breaking the law without reflecting on the consequences of their actions. These flaws have led to a bigger criminal act.

Juvenile students are undergoing the learning process to understand their life without knowing that they did a lot of mistakes because of their poor judgement. Juvenile students who are driven to commit in delinquency do such things because of conflict and psychological stress that they received and are unable to perceive parents as a safe haven $[31,39]$. Interference and lack of communication between parents and children caused them to rebel and lead them to delinquent behaviours. The desire to try out new things, wanting to have freedom and attention have 
unintentionally raised the act of skipping school and other dangerous activities that risk others and their own life. Therefore, by involving themselves with this delinquent behaviours, students will just waste their life, put their family to shame and affect their academic achievement.

Hence, it clearly shows that parenting styles have influenced the development of children's behaviours. The findings of this study also show that authoritarian parenting style has a significant relation with the increasing level of delinquent behaviours. Other than that, peer is also one of the factors that influenced the students to be entangled in this delinquent behaviours. That is why each and every parents should be alert with their children's needs, responsible, educate them appropriately and show them the epitome of good people so that the children will be excellent and have a noble character to lead their future.

\section{Conclusions}

Parenting style is a process of educating and keeping the children's behaviours in control. Parents should choose the suitable way according to the situations to educate their children. This is because children nowadays are more exposed to foreign cultures and inputs which are beyond their expectation. Parents do not only play a role as a family member, but also as a friend for their children so that intimate and close relationship can be nurtured easily. Children will always be our responsibility to guide and speak with them about problems or rules that must be obeyed to avoid them from feeling like they are being forced or constrained. Cooperation and tolerance between parents and children will reduce the risk of being embroiled with immoral culture. Thus, it is expected that this study will give an awareness to the parents especially, so that they can add more knowledge about suitable parenting styles to ensure that their children are on the right track and can be mould correctly. Besides, future research is suggested to look into the relationship between authoritarian parenting style and anti-social behaviour of juvenile students. In addition, further study shall be conducted on the environmental factors that influence juvenile students and their delinquent behaviours. This study is strictly needed to investigate the dispositions that lead juvenile students to commit the anti-social behaviours. Hopefully this study can help all related parties to handle and prevent delinquent behaviours among juvenile students.

\section{Acknowledgement}

This study was funded by PP-FPEND- 2020, Faculty of Education, Universiti Kebangasaan Malaysia. Acknowledgment are also addressed to all who have participated in this study especially to all the respondents.

\section{REFERENCES}

[1] Ahmad Faqih Ibrahim, Ummi Nuwairah Norismail, Mustafa Kamal Amat Misra \& Muhammad Hilmi Mat Johar. The Level of Parental Affection Towards Delinquent Adolescents. Jurnal Maw’izah, 2019.

[2] Anne Galletha, Mastering the Semi-Structured Interview and Beyond. New York: New York University Press, 2013. 244 pp. ISBN: 9780814732939

[3] Armsden, G. C. And m. T. Greenberg.. The Inventory of Parent and Peer Attachment: Individual Differences and Their Relationship to Psychological Wellbeing in Adolescence. Journal of youth and adolescence, vol.16, no. 5, pp. 427-454, 1987.

[4] Asmawati Desa, Fatimah Yusoff, Zainah Zamani, Nor Ba'yah Kadir. Parenting Skills, Family Functioning and Psychological Well-Being amongst Parents. Jurnal Sains Humanika, vol. 3, no. 1, pp. 99-105, 2015.

[5] Baglivio, M. T., \& Epps, N. The Interrelatedness of Adverse Childhood Experiences Among High-risk Juvenile Offenders. Youth Violence and Juvenile Justice, vol. 14, no. 3, pp. 179-198, 2016.

[6] Baumrind, D. Effects of Authoritative Parental Control on Child Behavior. Child Development, vol. 37, pp. 887-907, 1966.

[7] Baumrind, D. Current Patterns of Parental Authority. Developmental Psychology Monograph. vol. 4, no. 1, pp. 1-102, 1971 .

[8] Baumrind, D. The Influence of Parenting Styles on Adolescent Competence and Substance Use. Journal of Early Adolescence, vol. 11, no. 1, pp. 56-95, 1991.

[9] Creswell. J. W. \& Plano Clark. An Introduction to Mixed Methods Research. University of Nebrasca-Lincoln, 2007.

[10] David L. Morgan.. Focus Group As Qualitative Research. Second Edition, 1997.

[11] Diana Wulandari, Lee Jun Choi Sawan, Mohammad Syawal \& Narawi. The Influence of Parenting Styles Towards Truancy. Journal of Education and Social Sciences, vol. 9, 2018.

[12] Igbo, J. N., \& Ihejiene, M. A. Influence of Parenting Styles on Deviant Behaviors and Academic Achievement of Secondary School Students in Garoua, Northern Cameroun. International Journal of Educational Science and Research, vol. 4, no. 5, pp. 19-34, 2014.

[13] Izzah Nur Aida Zur Raffar, Salasiah Hanin Hamjah \& Adawiyah Ismail. Parents' Understanding In Parenting Skills Based On Islamic Perspective. Asean Journal of Civilizational Studies, 2019.

[14] Jose, C. Frsnguela. AG. Maneiro, L. Sobral, J. Effect of Parenting Practices through Deviant Peers on Nonviolent and Violent Antisocial Behaviours in Middle and Late-adolescence. The European Journal of Psychology Applied to Legal. vol. 9, no. 2, pp. 75-82, 2017. 
[15] Junger-Tas J. Ethnic Minorities and Criminal Justice in The Netherlands. Crime and Justice vol. 21, pp. 257-310. 1997. doi: $10.1086 / 449252$.

[16] "Annual Report of the National Anti-Drug Agency", Agensi Anti Dadah Kebangsaan. 2018.

[17] Landell, K. "Management by Menu". London Wiley and Son Inc. 1977.

[18] Maccoby, E., \& Martin, J. A. Socialization in The Context of The Family: Parent-child Interaction. In E. M. Hetherington (Ed), Handbook of Child Psychology. Socialization, Personality, and Social Development pp. 1-101, 1983.

[19] Mariani Omar dan Siti Sarah Hamzah. Parenting Styles Towards Children Among the Employees at Sultan Azlan Shah Islamic University College. Al Qimah Al Mudhafah The Journal of Management and Science. vol 2, 2016.

[20] Matevevic, M., Todorovic, J., \& Jovanovic, A. D. Patterns of Family Functioning and Dimensions of Parenting Styles, Procedia-Social and Behavioral Sciences. vo. 141, pp. 431 437, 2014

[21] Michael Thomas McKay. Parental Rules, Parent and Peer Attachment, and Adolescent Drinking Behaviors. Informa Healthcare. UK, 2015.

[22] Mike Tapia, Leanne Fitfal Alarid \& Courtney Clare. Parenting Styles and Juvenile Delinquency: Exploring Gender Relationship Juvenile Family Court, 2018, https://doi.org/10.1111/jfcj.12110

[23] Militsa Nikiforou, Stelios N. Georgiou \& Panayiotis Stavrinide. Attachment to parent and peers as a parameter of bullying and victimization. Journal of Criminology. 2013.

[24] Mohamad Faizal Mohamad dan Mohd Zaki Ishak. Sexual Relationship Among Students: A Case Study. Seminar Kebangsaan Integriti Keluarga Malaysia, 2014

[25] Nik Nursyairah Nik Nordin \& Mohd Nasir Selamat. Students' Delinquency Behaviours and the Influencing Factors. Jurnal Wacana Sarjana, vol. 2, no. 1, pp. 1-9, 2018.

[26] Nor Jumawaton Shahruddin, Mariani Mansor, Zainal Madon dan Hanina Halimatusaadiah Hamsan. The Relationship Between Peers Influence, Self Esteem, Locus of Control and Attitude Towards Sexual Behaviours. Akademika, vol. 88, no. 2, pp. 81-94, 2018.

[27] Norhayati Ibrahim, Rozmi Ismail, Noh Amit, Noordeyana Tambi, Mohd Nasir Selamat, Muhammad Ajib Abd Razak, Nor Azri Ahmad, Nurul Shafini Shafurdin. A Comparison of Knowledge Level, Attitude and Drug Effects Among Risky School Teenagers. Jurnal Psikologi Malaysia. vol. 38, no. 2, pp. 1-11, 2018.

[28] Norhayati Mat Ghani \& Suriati Ghazali. 2015. Reactions of Youtube Users Towards Bully Among Malaysian Teenagers. Jurnal Sains Humanika, vol 6, no 1, 2015.

[29] Nur Fatin Kamaruzaman, Muhammad Ajib Abd Razak \& Fatimah Yusooff. The Relationship Between Parenting Teenagers Behavioural Dimension Towards Psychological Well-Being Among Parents. Simposium Kebudayaan Dan Kerjasama Indonesia-Malaysia, 2015.

[30] Nurul Aini Binti Omar \& Siti Marziah Zakaria. The
Relationship Between Parenting Styles, Emotional Intelligence and Children's Behavioural Problems: A Review. Jurnal Wacana Sarjana. vol. 2, no. 3, pp. 1-7 1, 2018.

[31] Nurul Hudani Md. Nawi, Anuar Din \& Puteri Hayati Megat Ahmad. Family Situational Factor and Its Relationship with Self Appreciation Among Students. International Journal of Education Vol. 1, 37 - 56, 2019.

[32] Pavalache, M. I. \& Tirdia, A. F. Parental Involvement and Intrinsic Motivation with Primary School Students. Procedia-social and Behavioral Sciences, vol.187, pp. 607 $612,2015$.

[33] Rika Aulya Purnama \& Sri Wahyuni. Attachments Towards Parents with Teenagers' Social Competency. Jurnal Psikologi, vol. 13, no. 1, 2017.

[34] Ritchie, J. \& Spencer, L. 1994. Qualitative data analysis for applied policy research" by Jane Ritchie and Liz Spencer in A.Bryman and R. G. Burgess [eds.] "Analyzing qualitative data", 1994, pp.173- 194

[35] Rosly Abas, Zaim Ahmad, Jamaludin Mustaffa, Kamarudin Ngah. Teenagers and Deviance Based on Public's Perspective. Prosiding $2^{\text {nd }}$ International Social Development Conference, 2016

[36] Rozmi Ismail, Nor Azri Ahmad, Fauziah Ibrahim \& Salina Nen. The Influencing Factors of Individual, Family and Social Environment In Behavioural Misused of Substance In Students. Jurnal Akademika, vol. 87, no.1, pp. 7-16, 2017.

[37] Siti Hajar Abu Bakar Ali, Noralina Omar, Siti Balqis Mohd Azam \& Zaitun Azman. Prevention Program Based on Parenting as A Response to Pregnancy Issues Among Teenagers. Journal of Social Administration, vol. 9, no. 1, pp. $1-28,2017$

[38] "The Statistics on Juveniles' Involvement and Cases", Institut Penyelidikan Pembangunan Belia Malaysia (IPPBM), 2018.

[39] Stefanos Mastrotheodoros, Jolien Van der Graaff1, Maja Deković, Wim H. J. Meeus, Susan Branje. Empirical Research. Parent-Adolescent Conflict across Adolescence: Trajectories of Informant Discrepancies and Associations with Personality Types. Journal of Youth and Adolescence, vol. 49, pp.119-135, 2019.

[40] Suzyliana Mamat. The Level of Emotional Intelligence Among Adolescents at Melaka Islamic University College. Jurnal Sosial Sains Malaysia. vol. 1, no. 1, 2016.

[41] Syah Rizal, Hamdi Ishak \& Najah Nadiah Amran. The Relationship Between Adolescents' Behaviour and Parental Practices. Persidangan dan Seminar Islam dan Sosial, 2017.

[42] Xinwen Bi, Yiqun Yang, Hailei Li, Meiping Wang, Wenxin Zhang \& Kirby Deater-Deckard. Parenting Styles and Parent-adolescent Relationships: The Mediating Roles of Behavioral Autonomy and Parental Authority. Front. Psychology, 2018. https://doi.org/10.3389/fpsyg.2018.0218 7.

[43] W.N.Tan, Maizura Yassin. Parent's Roles and Parenting Styles on Shaping Children's Morality. Universal Journal of Educational Research. vol. 8, no 3C, pp. 70-76. 2020. 
[44] Zakri \& Saemah. Meta-behavioural Skills and Decision Making Skills Among Students With Disciplinary Issues and Not. Jurnal Pendidikan Malaysia, vol. 40, no. 2, pp. 175-183, 2015.
[45] Zarina Othman dan Mohamad Daud Druis. Threats of Drug Syndicates Towards Juvenile in Malaysia. Geografia Malaysian Journal of Society and Space, vol. 11, no. 1, pp. 62-72, 2015 